\title{
Como as empresas integrantes da Carteira ISE avaliam o retorno do investimento social privado
}

\section{How the companies integrating the ISE Portfoly evaluate the return of private social investment}

\author{
DANIELA GENTIL* \\ GLERIANI TORRES CARBONE FERREIRA**
}

\section{RESUMO}

O investimento social privado (ISP) é um tema em ascensão, já considerado estratégico por muitas empresas da carteira ISE (Índice de Sustentabilidade Empresarial). Contudo, faz-se necessário um processo de avaliação de retorno do ISP a fim de garantir a manutenção ou ampliação dos recursos financeiros alocados, além de ser um instrumento avaliado positivamente nas análises desenvolvidas pela BOVESPA (Bolsa de Valores de São Paulo). Face ao exposto, o objetivo geral deste estudo foi analisar como as empresas integrantes da carteira ISE avaliam o retorno das ações de ISP que desenvolvem. Com relação à metodologia utilizada, optou-se por dois tipos de pesquisas: a primeira, exploratória em livros, artigos acadêmicos e relatórios de sustentabilidade, integrados ou socioambientais das empresas da carteira ISE. A segunda, por meio de pesquisa aplicada, qualitativa, explicativa com estudo de casos, onde se investigou como as empresas integrantes do ISE avaliam o retorno do ISP. Complementarmente, os resultados foram cruzados com as respostas fornecidas pelas

* ORCID iD http://orcid.org/0000-0001-6781-4664. URL http://orcid.org/0000-0001-6781-4664 FIA - Fundação Instituto de Administração. dgentil@terra.com.br .

** ORCID iD http://orcid.org/0000-0003-3725-3135. URL http://orcid.org/0000-0003-3725-3135

FIA - Fundação Instituto de Administração. gleriani.ferreira@gmail.com . 
empresas ao questionário do ISE - dimensão social. Como resultado, pôde-se avaliar a prática de avaliação do ISE, bem como, as estratégias adotadas pelas empresas e foi possível comprovar que a gestão do ISP deixa transparecer o quanto o tema está alinhado à estratégia da empresa.

Palavras-chave: Investimento Social Privado. ISE - Índice de Sustentabilidade Empresarial. Responsabilidade Social Corporativa. Sustentabilidade.

\section{Abstract}

The private social investment (PSI) is a subject under development and already considered strategic by many companies in the ISE (index of corporate sustainability). The process of evaluating the return of the PSI is necessary for the maintenance or increase the financial resources, also it is positively ranked by the stock exchange of BOVESPA (São Paulo Stock Exchange). Thus, the general objective of this study was to analyze how the ISE portfolio companies evaluate the return on PSI. Regarding the methodology used, two types of researches were chosen: the first, exploratory in books, academic articles and sustainability reports, integrated and or socio-environmental of the companies on the ISE portfolio. The second, was through applied, qualitative, explanatory research with study cases, where was investigated how companies area part of the ISE portfolio evaluate the return on private social investment. As a complement, it also analyzed the answers provided by the companies to the ISE questionnaire - social dimension. As a result, it is possible to evaluate the ISE evaluation practice, as well as the strategies adopted by the companies and it was possible to prove that the management of the ISP shows how much the theme is aligned with the company's strategy.

Key-words: Private Social Investment. ISE - Index of Corporate Sustainability. Corporate Social Responsibility and Sustainability.

\section{INTRODUÇÃo}

As ações sociais realizadas pelas empresas passaram a fazer parte dos diferenciais competitivos de muitas delas, pois, se por um lado elas buscam minimizar seus impactos no meio ambiente, por outro, podem promover o desenvolvimento sustentável das comunidades, gerando crescimento econômico e também social. 
Diante disso, cada vez mais os projetos sociais ganham importância, sejam eles articulados pelo governo, pela iniciativa privada ou pela sociedade civil organizada em suas mais diferentes formas e áreas de atuação (COELHO, 2007).

Nos últimos anos, o ISP (Investimento Social Privado) no Brasil vem passando por mudanças que refletem o amadurecimento do segmento social e reforçam algumas tendências, como o contexto da avaliação de programas sociais (OTERO, 2012). Contudo, na medida em que o ISP cresce, faz-se necessária a realização de avaliação da performance das atividades sociais realizadas pelo setor privado.

Para se analisar comparativamente a performance das empresas sob o aspecto da sustentabilidade corporativa, deve-se incluir aspectos relacionados com eficiência econômica, equilíbrio ambiental, justiça social e governança corporativa. Nesse sentido, Índice de Sustentabilidade Empresarial (ISE) aplicável às empresas listadas na Bolsa de Valores de São Paulo passou a ampliar o entendimento acerca do tema, diferenciando-os no que tange ao compromisso com o desenvolvimento sustentável e empresarial (ISE-BVMF, 2016).

Assim, o crescimento do interesse pelo tema nos últimos anos no Brasil, somado à possibilidade de alcançar um diferencial competitivo valorizado, inclusive, pelo ISE, denota uma aceleração no volume de ações sociais desenvolvidas no âmbito empresarial.

Para a decisão sobre os investimentos a serem realizados, bem como, para a avaliação dos resultados e impactos, pressupõe-se que as empresas que realizam tais ações estejam empenhadas no mapeamento dos resultados objetivos, bem como, na mensuração dos impactos. Tal questionamento motivou este estudo, que busca responder à seguinte pergunta de pesquisa: como as empresas da carteira ISE 2016 avaliam o retorno do investimento social privado?

\section{REFERENCIAL TEÓRICO}

Nos anos 1930, com a era da industrialização e a urbanização, as questões sociais intensificaram-se e surgiram muitas entidades da sociedade civil. Em 1935, foi promulgada a lei de declaração de utilidade pública, atribuindo um papel importante ao Estado no que diz respeito às instituições filantrópicas (KARKOTLI, 2007; PIMENTEL, 2011). 
Nas duas décadas seguintes, de 1940 e 1950, observou-se o florescimento das organizações partidárias criadas no período do sindicalismo (PIMENTEL, 2011). Nos vinte anos seguintes, de 1960 a 1980, predominaram a ajuda externa de agências internacionais (não governamentais) de cooperação e desenvolvimento (BNDES, 2001). Na mesma época, surgiram os movimentos sociais que reivindicavam os seus direitos.

No final dos anos 1980, com a redemocratização do Brasil e o estabelecimento da Constituição, a carência das ações sociais desenvolvidas pelo Estado fez surgir aumento significativo no número de organizações não governamentais (PIMENTEL, 2011; GIFE, 2015). Karkotli (2007) reforça que, com a promulgação da Constituição Federal, estabeleceram-se com maior vigor os direitos sociais, o que ficou amplamente explicitado com a realização posterior da Conferência Eco-92, no Rio de Janeiro.

Assim, a década de 1990 foi marcada pelo crescimento da participação da iniciativa privada nas políticas sociais, demonstrando maior sensibilização das empresas na redução das carências não contempladas pelos mecanismos governamentais. Da mesma forma, crescia a pressão exercida por entidades não governamentais e institutos de pesquisa, conferindo maior relevância ao tema da responsabilidade social, com ampla difusão no terceiro setor e no ambiente empresarial (GIFE, 2015; VOLTOLINI, 2007).

Nos anos 2000, iniciou-se uma mudança de posicionamento dos investimentos sociais das empresas, passando a adotar técnicas de inteligência social com foco em parcerias diversificadas de atuação para promover relacionamento estratégico com as comunidades do entorno (PIMENTEL, 2011).

Com o cenário em plena expansão, o ISE foi lançado no ano de 2005, financiado pela International Finance Corporation (IFC), braço financeiro do Banco Mundial. Trata-se de uma ferramenta para análise comparativa da performance das empresas listadas na Bolsa de Valores, sob o aspecto da sustentabilidade corporativa, ancorada em eficiência econômica, equilíbrio ambiental, justiça social e governança corporativa (ISE-BVMF, 2016).

$\mathrm{O}$ índice, resultante das diversas análises, amplia o entendimento sobre empresas e grupos comprometidos com a sustentabilidade, 
além de diferenciar os participantes em termos de engajamento com o desenvolvimento sustentável, equidade, transparência e prestação de contas, entre outros temas que colaboram para o estabelecimento do nível de desempenho empresarial nas dimensões econômico-financeira, social, ambiental e de mudanças climáticas (ISE-BVMF, 2016).

\subsection{Responsabilidade Social Corporativa (RSC) ou Responsa- bilidade Social Empresarial (RSE)}

De uma maneira generalizada, a responsabilidade social busca estimular o desenvolvimento do cidadão e fomentar a cidadania individual e coletiva, com ações extensivas a todos os que participam da vida em sociedade - indivíduos, governo, empresas, grupos sociais, movimentos sociais, igreja, partidos políticos e outras instituições (MELO NETO; FROES, 2004).

Em se tratando de Responsabilidade Social Corporativa - RSC, também chamada de Responsabilidade Social Empresarial - RSE, o foco passa a ser direcionado para o comportamento ético e a busca pela qualidade nas relações que a empresa estabelece com todos os seus públicos-alvo. Podendo ter associação direta ou indireta com o negócio da empresa, incorporando-se à orientação estratégica do negócio, refletindo desafios éticos para as dimensões econômica, ambiental e social (KARKOTLI, 2007).

Para Porter e Kramer (2006), a realização de RSC por empresas socialmente responsáveis pode ser responsiva ou estratégica. A empresa responsiva atua por meio de projetos e ações no seu entorno e reduz os seus impactos e, na empresa estratégica, as práticas da cadeia de valor estão totalmente integradas, situação em que a RSC faz parte do negócio, ficando difícil distingui-la da empresa.

Uma atitude mais responsável diante da RSC pode fortalecer a marca ao longo do tempo, proporcionando um crescimento sustentável; assim, as ações de RS aliadas à comunicação podem reduzir os riscos e adicionar valor à imagem da empresa (OLIVEIRA, 2013; CALDAS; TAMBOSI FILHO; VIEIRA, 2014). Esse valor adicionado à marca, muitas vezes, gera capital ou imagem reputacional positiva associada à empresa.

A RSC e o ISP relacionam-se, mas não são equivalentes. O ISP realizado pela empresa beneficia prioritariamente a comunidade e 
faz parte da RS da empresa (PIMENTEL, 2011). Portanto, pode-se dizer que o escopo do ISP é mais restrito que o da RSC, pois o seu olhar dirige-se para as comunidades de relacionamento da empresa.

\subsection{Investimentos social corporativo (ISC) ou Investimento Social Privado (ISP)}

O investimento social corporativo - ISP, também chamado de investimento social privado - ISP, trata do uso planejado, monitorado e voluntário de recursos privados - provenientes de pessoas físicas ou jurídicas - em projetos de interesse público (GIFE, 2015). Incluem-se nesse universo as ações sociais protagonizadas por empresas, fundações e institutos de origem empresarial ou institutos, por famílias ou indivíduos. Sua origem também está associada às empresas que, diretamente ou por meio de parcerias com organizações da sociedade civil, passaram a desempenhar tais ações de investimentos, além de prestação de serviços a partir da mobilização de interesses coletivos e objetivos compartilhados (ANDION; BECKER; VICTOR, 2012).

Para Milano Filho (2008), o ISP é um conceito que apresenta diferentes interpretações, mas é caracterizado, basicamente, pela transferência voluntária de recursos de empresas privadas para projetos sociais, ambientais e culturais de interesse público.

A empresa é um importante agente no desenvolvimento econômico, por meio de geração de empregos e podendo ter um papel mais amplo socialmente, quando realiza ações de investimento social privado nas comunidades em que atua.

A comunidade para a qual o ISP é direcionado pode ser definida, no sentido genérico, como qualquer grupo com características comuns e, no sentido específico da sociologia, como a população de área de vida em comum (FREIRE, 2009).

A empresa pode se aproximar das questões sociais críticas para o seu negócio por meio do Investimento Social Privado Estratégico (ISPE), desde que isso seja feito de forma alinhada às diretrizes de sustentabilidade e às estratégias de negócio da empresa (PIMENTEL, 2011). Quando o ISP está alinhado à estratégia do negócio, ele passa a ser estratégico, pois permeia todos os processos e áreas da empresa e tem alto envolvimento da liderança. 


\subsection{Avaliação do retorno do investimento em Responsa- bilidade Social Corporativa ou investimento Social Privado}

A avaliação do retorno de investimentos em responsabilidade social era utilizada, em um primeiro momento, como forma de conhecer a realidade por meio de medições quantitativas, em profunda associação com o positivismo lógico. Depois, ela foi empregada como instrumento para descrever processos, comportamentos e fenômenos, ancorando a avaliação com o positivismo lógico (OTERO, 2012).

Considera-se que a avaliação não é um elemento isolado na gestão das empresas e, quando elas têm baixa institucionalização, planejamentos pouco consistentes e investimentos descontínuos, são pouco propensas a desenvolver processos avaliativos efetivos, ou seja, a qualidade da avaliação é causa e efeito do fortalecimento e maturidade institucionais (DEGENSZAIN, 2013).

Já o indicador tem como tarefa básica expressar, da forma mais simples possível, determinada situação que se deseja avaliar, pois o resultado dele é uma fotografia de dado momento, e demonstra, sob uma base de medida, aquilo que está sendo feito, ou o que se projeta para ser feito (FERNANDES, 2004).

Quanto ao uso de indicadores na área social corporativa, existem duas formas de avaliação; a primeira forma é focada em métodos que avaliam o índice de reputação, ancorada na análise dos indicadores, e a segunda, qualitativa, é realizada por observadores especializados, em um processo metodológico em que o avaliador aplica os mesmos critérios para cada empresa (COCHRAN; WOOD, 1984 apud DAHER, 2006).

O uso do método, seguido de um protocolo de divulgação expresso em publicações como relatórios anuais, tornou possível a observação do desempenho das atividades que a empresa desenvolve, bem como, a aferição de um resultado. A observação pode ser a percepção de que um item em particular foi discutido, e também uma análise acerca dos aspectos qualitativos e/ou só quantitativo considerados.

\section{METódo do ESTUdo}

A pesquisa foi realizada em duas etapas. A primeira, compreendida por uma pesquisa exploratória, orientada a partir dos seguintes procedimentos: 
a) referencial teórico acerca dos termos ISP, RSC ou RSE, Avaliação de Retorno do ISP e Sustentabilidade.

b) relatórios de sustentabilidade (ou com denominação equivalente) das empresas que compõem a amostra;

c) artigos que tratam da carteira ISE, com pesquisas realizadas no período de 2006 a 2015, devidamente focados nos temas ISP, RSC e/ou Sustentabilidade.

O procedimento descrito no item c apresentou prioritariamente artigos focados na dimensão econômica (financeira), com um número inferior de artigos abordando a dimensão social, mais aderente ao tema deste estudo. Assim, dos 13 artigos pesquisados, aproveitaram-se seis.

Na segunda etapa de pesquisa, optou-se por uma pesquisa qualitativa aplicada quanto à natureza, uma vez que se objetiva gerar conhecimentos para aplicação na prática, dirigidos à solução de problemas específicos, envolvendo verdades e interesses locais (PRODANOV; DE FREITAS, 2013). Com relação aos objetivos, selecionou-se a pesquisa explicativa, uma vez que se buscou aprofundar o conhecimento de como as empresas da carteira ISE 2016 avaliam o retorno do ISP.

Quanto ao procedimento técnico, optou-se por estudo de caso, sendo aquele que possibilita estudar em profundidade o grupo, organização ou fenômeno, considerando suas múltiplas dimensões (GIL, 2009). No que se refere à classificação, trata-se de um estudo de caso explicativo, pois visa responder a uma questão acerca de "como" as empresas integrantes da carteira ISE 2016 avaliam o retorno do ISP.

Optou-se por uma amostra não probabilística, sendo aquela em que a seleção dos participantes é ancorada em suas características ou experiências, atitudes ou percepções únicas (COOPER, SCHINDER, 2011). Entre uma população de 35 empresas pertencentes à carteira ISE 2016 (a empresa OI foi retirada da carteira no decorrer do ano), a amostra foi composta pelas 14 empresas que aceitaram participar da pesquisa, respondendo positivamente ao convite eletrônico direcionado para o responsável da área de sustentabilidade.

Embora as empresas tenham autorizado a utilização de seus respectivos nomes nesta pesquisa, algumas delas pediram que suas 
respostas fossem divulgadas, sempre consolidadas com as demais ou de forma anônima. Assim sendo, para não expor qualquer dos entrevistados, optou-se por identificar as empresas por letras e não por nome.

As entrevistas foram realizadas no período de 20 de julho a $1^{\circ}$. de novembro de 2016, com reuniões presenciais, telefonemas ou trocas de e-mails, conforme a escolha de cada entrevistado (Quadro 1).

Quadro 1 - Amostra das empresas participantes da pesquisa

\begin{tabular}{|c|c|c|c|}
\hline Empresa & Segmento & Entrevista & Função do Entrevistado: \\
\hline AES Tietê & Energia Elétrica & Telefone & Analista de sustentabilidade sênior \\
\hline $\begin{array}{l}\text { AES } \\
\text { Eletropaulo }\end{array}$ & Energia Elétrica & Telefone & Analista de sustentabilidade \\
\hline $\begin{array}{l}\text { Banco do } \\
\text { Brasil }\end{array}$ & Banco Comercial & Telefone & $\begin{array}{l}\text { Gerente executivo de sustentabili- } \\
\text { dade }\end{array}$ \\
\hline Braskem & $\begin{array}{l}\text { Química e Petro- } \\
\text { química }\end{array}$ & E-mail & $\begin{array}{l}\text { Gerente de desenvolvimento sus- } \\
\text { tentável }\end{array}$ \\
\hline Copel & Energia Elétrica & E-mail & $\begin{array}{l}\text { Gerente do departamento de acio- } \\
\text { nistas }\end{array}$ \\
\hline CPFL & Energia Elétrica & Telefone & $\begin{array}{l}\text { Gerente de sustentabilidade corpo- } \\
\text { rativa }\end{array}$ \\
\hline $\begin{array}{l}\text { Engie } \\
\text { Brasil }\end{array}$ & Energia & E-mail & $\begin{array}{l}\text { Não autorizado a divulgar pelo } \\
\text { entrevistado }\end{array}$ \\
\hline Light & Energia Elétrica & Telefone & Especialista em sustentabilidade \\
\hline $\begin{array}{l}\text { Lojas } \\
\text { Renner }\end{array}$ & Varejista de Moda & Telefone & Diretor executivo \\
\hline Natura & Cosméticos & Pessoalmente & Diretor de sustentabilidade \\
\hline Oi & Telecomunicações & E-mail & Gerente de Sustentabilidade \\
\hline \multirow[t]{2}{*}{ Santander } & Banco Comercial & Telefone & Gerente de sustentabilidade \\
\hline & Banco Comercial & E-mail & $\begin{array}{l}\text { Gerente de desenvolvimento sus- } \\
\text { tentável }\end{array}$ \\
\hline $\begin{array}{l}\text { Sul-Amé- } \\
\text { rica }\end{array}$ & Seguros & $\begin{array}{l}\text { Conference } \\
\text { call na sede } \\
\text { da empresa }\end{array}$ & Consultora de sustentabilidade \\
\hline Telefônica & Telecomunicações & Telefone & Gerente de sustentabilidade \\
\hline
\end{tabular}

Fonte: os autores. 
Como uma segunda fonte de evidência, após a coleta das informações via entrevistas por questionário semiestruturado, fez-se também uma segunda análise, englobando quais foram as respostas que as empresas entrevistadas deram no questionário do ISE 2016, especificamente na Dimensão Social.

Como terceira fonte de evidência, realizou-se uma análise comparativa com as informações constantes nos relatórios de sustentabilidade (ou com denominação equivalente) das empresas ISE 2016. Em função das diferentes abordagens entre as informações apuradas na pesquisa qualitativa e os dados dos relatórios, realizou-se uma análise comparativa, buscando a equivalência dos aspectos analisados.

\section{ANálise de RESUltados}

A análise dos dados foi precedida de uma subdivisão em cinco tópicos, a fim de favorecer a comparabilidade dos aspectos atendidos, bem como, o desempenho que cada um dos respondentes apresentou, a saber:

\subsection{O entendimento de como é realizada a gestão do ISP nas empresas integrantes do ISE 2016}

Considerando que um dos objetivos específicos deste estudo é explorar os procedimentos de gestão do ISP nas empresas da carteira ISE 2016, perguntou-se qual área da empresa é responsável pelo ISP, e se levantou que o ISP está centralizado: de 14 empresas pesquisadas, sete inserem-no na área de sustentabilidade; em quatro delas, ele está sob a responsabilidade de áreas que não estavam relacionadas na pesquisa, mas foram mencionadas a seguir pelos entrevistados, e, em três das empresas, apurou-se que o ISP tem a gestão compartilhada entre duas áreas.

Como mencionado no referencial teórico por Pimentel (2011), a empresa pode se aproximar das questões sociais críticas para o seu negócio por meio do Investimento Social Privado Estratégico, desde que isso seja feito de forma alinhada às diretrizes de sustentabilidade e às estratégias de negócio. $\mathrm{O}$ estudo identificou que, em dez empresas, eles são definidos por política interna, em três 
por diretriz e em uma por outra forma de definição. Observou-se, na interpretação dos dados da pesquisa, que todas as empresas da amostra têm um critério formal para a definição dos temas de ISP, ou seja, o tema segue uma política interna, diretriz ou tendência de mercado e matriz de materialidade do relatório de sustentabilidade.

No que se refere ao tema mais valorizado para receber investimentos, houve destaque para a educação, com enfoque de três empresas da amostra. O segundo tema foi saúde, citado por duas empresas e cultura mencionado por uma empresa. Três empresas da amostra aportam investimentos em mais de um tema.

A análise comparativa entre as respostas das empresas sobre qual é o tema prioritário para o ISP, versus os temas publicados nos seus respectivos relatórios de sustentabilidade, integrados ou socioambientais, demonstrou que os temas conferem integralmente em 12 empresas e em apenas duas delas, que estão inseridas no grupo que responderam outros temas, as informações conferem parcialmente.

Confirmando a teoria de Melo Neto e Froes (2004), apurou-se que tipo de projeto as empresas mais utilizam. O resultado mostra que sete delas usam projetos com leis de incentivo, seis realizam projetos próprios e uma, outros tipos de projetos.

Nota-se que, em relação aos tipos de projetos utilizados, $50 \%$ dos entrevistados das empresas disseram que usam mais os projetos incentivados e $42,86 \%$, projetos próprios, embora, segundo os depoimentos já relatados, de duas das empresas, elas pretendem deixar de realizar projetos próprios por razões diferentes, e apenas 7,14 \% fazem outros tipos de projetos.

Com relação aos valores anuais dedicados ao ISP, 100\% da amostra, ou seja, as 14 empresas declararam, ao responder que o valor investido representa menos de $5 \%$ da receita líquida. No que se refere à triangulação dos dados referentes aos valores investidos, realizou-se uma verificação dos valores mencionados pelos respondentes deste estudo, em comparação com os dados referidos nos relatórios emitidos pelas respectivas empresas. Com exceção de uma empresa que não disponibilizou o dado na publicação, todos os valores dados conferem. 


\subsection{A relação das empresas com as comunidades}

Confirmando a teoria de Peter Drucker (2001), incluíram-se cinco perguntas no questionário de pesquisa, as quais buscavam identificar como é a relação da empresa com a comunidade do entorno. Segundo o autor, toda empresa deve assumir plena responsabilidade por seu impacto nos funcionários, no ambiente, nos clientes e em tudo aquilo e em todos que forem afetados por ela. Duas dessas perguntas tinham como objetivo apurar se a empresa realiza o levantamento das necessidades das comunidades do entorno e, se sim, como ela o faz.

Conforme apurado do total de 14 empresas, 10 responderam que realizam levantamento de necessidades das comunidades do entorno, contra quatro que não o fazem, o que confirma a teoria de Reis e Medeiros (2012), que preconiza que as empresas são agentes de promoção do desenvolvimento econômico, colaborando na criação de uma consciência global que possibilita engajar todos, com preservação do meio ambiente, do patrimônio cultural, da promoção dos direitos humanos e da construção de uma sociedade economicamente próspera e socialmente justa.

Quanto à forma de realização do levantamento de necessidades das comunidades, das 10 empresas que o realizam, apurou-se que quatro utilizam levantamento interno, duas fazem levantamento por meio de terceiros e quatro utilizam ambos os indicadores (Tabela 1).

Tabela 1 - Como as empresas fazem os levantamentos das necessidades do entorno das comunidades

\begin{tabular}{|l|l|}
\hline Forma de levantamento de necessidades & Número de empresas \\
\hline Levantamento interno & 4 \\
\hline Levantamento feito por terceira parte & 2 \\
\hline Utiliza de ambos (interno e feito por terceiros) & 4 \\
\hline Não faz levantamento & 4 \\
\hline
\end{tabular}

Fonte: dados da pesquisa. 
Concluiu-se que $71,42 \%$ das empresas realizam o levantamento de necessidades das comunidades. Já com relação à forma como ele é feito, observou-se que existe uma divisão, 28,57\% da amostra fazem por levantamento interno, $14,28 \%$, por terceira parte e $28,57 \%$ via utilização de ambos os indicadores.

Por meio do questionário de pesquisa, buscou-se identificar como as empresas da carteira ISE 2016, após implementarem os seus projetos sociais, avaliam a satisfação das comunidades do entorno. Apurou-se que, das 14 empresas da pesquisa, três utilizam levantamento interno, três fazem levantamento por terceira parte, outras quatro usam ambos os levantamentos e quatro não avaliam a satisfação das comunidades com relação aos projetos sociais implementados (Tabela 2).

Tabela 2 - Como as empresas fazem os levantamentos de satisfação das comunidades

\begin{tabular}{|l|l|}
\hline Forma de levantamento da satisfação: & Número de empresas: \\
\hline Levantamento interno & 3 \\
\hline Levantamento feito por terceira parte & 3 \\
\hline Utiliza de ambos (interno e feito por terceiros) & 4 \\
\hline Não faz levantamento & 4 \\
\hline
\end{tabular}

Fonte: dados da pesquisa.

Concluiu-se que o levantamento de satisfação das comunidades é realizado por $71,43 \%$ da amostra, um percentual alto, que confirma a teoria de Szekely (2013), demostrando a aderência que a maioria das empresas da carteira ISE 2016 tem em relação à avaliação dos impactos nas comunidades, ou seja, se elas estão ou não atendendo às reais necessidades dos seus entornos.

Já quanto à forma como o procedimento é feito, das dez empresas que realizam o levantamento de satisfação, quatro utilizam ambos os indicadores (internos e feitos por terceira parte), três usam indicadores internos e três fazem uso de indicadores apurados por terceiros, não existindo, assim, uma preferência muito grande por uma ou outra forma. 
Em uma segunda análise, comparando as formas de levantamento utilizadas tanto para as necessidades quanto para a satisfação das comunidades, Tabela 3, percebe-se certa semelhança tanto para o levantamento de um, como do outro.

Tabela 3 - Análise comparativa dos levantamentos de necessidades e satisfação das comunidades

\begin{tabular}{|l|l|l|}
\hline Formas de levantamento & Necessidades & Satisfação \\
\hline Levantamento interno & 4 & 3 \\
\hline Levantamento feito por terceira parte & 2 & 3 \\
\hline Utiliza de ambos (interno e feito por terceiros) & 4 & 4 \\
\hline Não faz levantamento & 4 & 4 \\
\hline
\end{tabular}

Fonte: dados da pesquisa.

Percebeu-se que houve duas semelhantes entre o levantamento de necessidades e de satisfação, em que quatro empresas utilizam de ambos os modelos (interno e realizados por terceira parte) e também que quatro empresas da amostra não fazem levantamentos nem de necessidades, nem de satisfação.

No levantamento de necessidades, o levantamento interno teve a maior pontuação, com aderência de quatro empresas; já no levantamento de satisfação houve empate, com três empresas para interno e três que utilizam serviços de terceira parte. Assim sendo, por meio das respostas às perguntas de pesquisa, atingiu-se o objetivo específico, como é feita a gestão do ISP pelas empresas da carteira ISE.

Com foco no objetivo geral do estudo, que era analisar como as empresas da carteira ISE 2016 avaliam o retorno do ISP e tendo como referência a teoria de Melo Neto e Froes (2004), que afirmam que a forma como é feita a avaliação do ISP é muito importante - exige um procedimento para apuração eficiente sobre o retorno dele e, sem uma metodologia eficiente, não se consegue apurar os resultados, foi realizada a pergunta 10 do questionário.

Conforme demostrado na Tabela 4, apurou-se que, das 14 empresas, 10 responderam que avaliam o retorno do Investimento Social Privado, ou seja, $71,43 \%$ da amostra, contra $28,57 \%$ que não 
avaliam. Das dez empresas que avaliam, cinco utilizam indicadores internos, quatro fazem uso de indicadores internos e externos e uma usa apenas indicadores apurados por terceira parte.

Tabela 4 - Como as empresas avaliam o retorno do ISP

\begin{tabular}{|l|l|}
\hline Formas de avaliação do retorno do ISP & $\begin{array}{l}\text { Número de } \\
\text { empresas }\end{array}$ \\
\hline Indicadores internos & 5 \\
\hline Indicadores apurados por terceira parte & 1 \\
\hline $\begin{array}{l}\text { Utiliza de ambos (internos e apurados por tercei- } \\
\text { ros) }\end{array}$ & 4 \\
\hline Não utiliza de nenhuma avaliação & 4 \\
\hline
\end{tabular}

Fonte: dados da pesquisa.

Concluiu-se que, respondendo ao objetivo geral deste estudo e confirmando a teoria de Melo Neto e Froes (2004) - que destacam que a forma como é feita a avaliação do retorno do ISP é muito importante e exige um procedimento -, que existe uma preocupação por parte das empresas da carteira ISE 2016 em relação à avaliação do retorno do ISP, como já mencionado, considerando-se que 71,43\% da amostra avalia o retorno do ISP.

Contudo, quanto a qual indicador utilizar, não existe um consenso, uma vez que todas as dez empresas que realizam a avaliação usam indicadores, sendo que 35,71\% utilizam indicadores internos realizados por elas próprias, $28,57 \%$, fazem uso de ambos os indicadores (internos e apurados por terceiros) e 7,15\%, indicadores apurados por terceira parte. $\mathrm{O}$ observado confirma, assim, também a teoria de Fernandes (2004), sobre a importância de se utilizar de indicador, quando se tem determinada situação que se deseja avaliar, pois o resultado demonstra, sob uma base de medida, aquilo que está sendo feito.

Para investigar sobre os impactos que as ações de ISP realizadas têm nas comunidades, apurou-se que apenas uma empresa respondeu afirmativamente, apontando as contribuições para a melhoria da qualidade de vida das pessoas. As treze demais empresas da 
amostra afirmaram que contribuem de fato para o desenvolvimento sustentável das comunidades e seis detalharam suas práticas. Assim, $92,85 \%$ da amostra declara que suas ações geram desenvolvimento sustentável no entorno.

\subsection{0 envolvimento da alta direção das empresas com o In- vestimento Social Privado}

Buscou ainda apurar se todas as ações de ISP estão associadas à estratégia da empresa e está alinhada à teoria de Porter e Kramer (2006), em que a realização de Responsabilidade Social por empresas socialmente responsáveis pode ser responsiva ou estratégica. A empresa responsiva atua por meio de projetos sociais no seu entorno e minimiza seus impactos e a estratégia, o tema social é tão importante que faz parte da empresa.

Como resultado, conclui-se que 11 empresas, os equivalentes a 78,57 \% da amostra, segundo a teoria de Porter e Kramer (2006), são consideradas "empresas estratégicas", pois suas ações de ISP estão alinhadas à estratégia dos seus respectivos negócios.

Com base na teoria de Pimentel (2011), bem como, tendo como referência um dos objetivos secundários deste estudo, por meio do questionário de pesquisa, que visava identificar como é o envolvimento da alta direção da empresa com o ISP.

Após as entrevistas, apurou-se, conforme Tabela 5, que o envolvimento da alta direção com o ISP foi relatado como alto por nove das empresas entrevistadas e, em cinco delas, como sendo médio.

Tabela 5 - O envolvimento da alta liderança com o ISP

\begin{tabular}{|l|l|}
\hline Envolvimento: & Número de empresas: \\
\hline Alto & 9 \\
\hline Médio & 5 \\
\hline Baixo & 0 \\
\hline
\end{tabular}

Fonte: dados da pesquisa. 


\subsection{Os impactos das ações de Investimento Social Privado em relação à imagem reputacional das empresas}

Por meio do questionário de pesquisa, foram elaboradas duas perguntas para atender a um dos objetivos específicos deste estudo, que é o de investigar se os impactos das ações de ISP contribuem para a imagem reputacional da empresa e, como complemento da apuração, qual seria a razão que mais traduz a realidade da empresa com relação ao assunto perguntado.

Segundo apurado, a razão que mais traduz a imagem reputacional do ISP para sete empresas da amostra é que ele promove relacionamento com a comunidade; para três das empresas, é que melhora a imagem de marca; para duas, traduz-se em outra razão, como o bem comum para a sociedade; e, para outras duas, é que todos os itens apresentados nesta pergunta de pesquisa são importantes (Tabela 6).

Tabela 6 - A imagem reputacional do Investimento Social Privado pode melhorar

\begin{tabular}{|l|l|}
\hline Itens que podem melhorar & Número de empresas \\
\hline Imagem de marca & 3 \\
\hline $\begin{array}{l}\text { Melhora os índices na Bolsa de Valores } \\
\text { (ISE) }\end{array}$ & 0 \\
\hline Motivação dos funcionários & 0 \\
\hline Relacionamento com a comunidade & 7 \\
\hline Todos são importantes & 2 \\
\hline Outra razão & 2 \\
\hline
\end{tabular}

Fonte: dados da pesquisa.

Nota-se que nenhuma das empresas entrevistadas citou que a imagem reputacional gerada pelo ISP é refletida na melhora dos índices da bolsa do ISE e, sim, elas deram maior destaque para o relacionamento com a comunidade. 


\subsection{Análise das respostas das empresas às perguntas do questionário ISE 2016 - dimensão social}

Como mencionado na metodologia de estudo, após a seleção das perguntas do questionário ISE 2016 - dimensão social que poderiam contribuir com este estudo, foi feita uma análise das respostas das empresas, de forma a assegurar a amplitude da pesquisa qualitativa (Tabela 7). ${ }^{1}$

Tabela 7 -Análise das perguntas do questionário ISE 2016 _ dimensão social

\begin{tabular}{|c|c|c|}
\hline & \multicolumn{2}{|c|}{ Resposta: } \\
\hline & Sim & Não \\
\hline \multicolumn{3}{|l|}{ SOC 15. A companhia promove iniciativas de Investimento Social Privado (ISP)? } \\
\hline a) Sin $\bigcirc$ b) Não & 13 empresas & \\
\hline \multicolumn{3}{|l|}{$\begin{array}{l}\text { SOC15.2Se SIMparaa PERGUNTA5, entre os critérios para definiçãodosinvestimentos sociaisa } \\
\text { companhia leva em conta a importância de se obter resultados concretos, e considera: }\end{array}$} \\
\hline \multirow{2}{*}{$\begin{array}{l}\text { a) A avaliaçlo dos resultados das inićativas apoiadas. } \\
\text { b) A auditoria sobre os resultados e gestão das iniciativas apoiadas. }\end{array}$} & 12 empresas & \\
\hline & 1 empresa & \\
\hline \multicolumn{3}{|l|}{ SOC 15.3 Se SIM para a PERGUNTA 15, em relação aos seus investimentos sociais, a compa hia: } \\
\hline \multirow[t]{2}{*}{ a) Define de forma clara a estratégia, indicadores e metas especificas para o investimento social. } & 12 empresas & 1 empresa \\
\hline & 13 empresas & \\
\hline \multicolumn{3}{|l|}{$\begin{array}{l}\text { SOC15.4Se SIM para a PERGUNTA1 5, a companhiarealizainvestimentossociais com recursos } \\
\text { disponíveis por meio de incentivos fiscais? }\end{array}$} \\
\hline a) $\operatorname{Sim}($ b) Não & 13 empresas & \\
\hline
\end{tabular}

Fonte: adaptado do questionário ISE 2016.

Concluiu-se que, embora o objetivo desta avaliação não fosse comparar as respostas das perguntas ISE 2016 em relação às da pesquisa qualitativa - até porque as perguntas, embora sejam semelhantes, não são idênticas, a análise das respostas nos deu mais subsídios informativos sobre como as empresas se posicionam frente ao ISP.

Percebeu-se que o tema vem sendo administrado de forma positiva, pois as empresas ressaltaram a importância de se obter resultados e terem metas específicas, como também a avaliação das iniciativas apoiadas foi citada pela maioria delas como essencial e,

1 O questionário da empresa Oi não estava disponível no site do ISE 2016 para consulta, por isso, ao invés de 14 empresas, temos 13 respostas para cada pergunta no total. 
da mesma forma, a frequência regular na apuração dos resultados e a utilização dos incentivos fiscais como ISP.

Finalmente, buscou-se relacionar quatro perguntas do questionário ISE 2016, integrantes da dimensão social com foco no tema pesquisado, com as perguntas da pesquisa qualitativa deste estudo. Por meio da exposição sistêmica e resumida das informações apuradas, foi possível conciliar os objetivos deste estudo: identificar como as empresas integrantes da carteira ISE avaliam o retorno do ISP; explorar como é feita a gestão do ISP nas empresas pertencentes à carteira ISE; identificar o envolvimento da alta direção com o tema; investigar se os impactos das ações do ISP contribuem para a imagem reputacional das empresas, além de comparar as respostas das empresas ao questionário ISE 2016 - dimensão social.

A Tabela 8 demonstra os principais resultados encontrados, relacionando as etapas de análise de resultados com os objetivos de pesquisa e com suas respectivas perguntas de pesquisa.

Após a análise de resultados neste item 4, segue-se para a conclusão do estudo, no item 5, com as considerações finais, limitações e contribuições para futuros estudos. 


\section{Tabela 8 - Resumo das respostas ao questionário ISE 2016 - dimensão social}

\begin{tabular}{|c|c|c|c|}
\hline $\begin{array}{l}\text { Etapas da análise de } \\
\text { resultados }\end{array}$ & Objetivos da pesquisa & $\begin{array}{l}\text { Perguntas } \\
\text { da pes- } \\
\text { quisa }\end{array}$ & Principais resultados da pesquisa \\
\hline $\begin{array}{l}4.1 \text { O entendimento } \\
\text { de como é realizada } \\
\text { a gestão do ISP nas } \\
\text { empresas integran- } \\
\text { tes ao } \\
\text { ISE } 2016\end{array}$ & $\begin{array}{l}\text { Analisar como as em- } \\
\text { presas integrantes da } \\
\text { carteira ISE } \\
2016 \text { avaliam o retorno } \\
\text { do } \\
\text { ISP }\end{array}$ & $1,3,6,7$ e 9 & $\begin{array}{l}\text { Na maioria das empresas da amostra, em sete } \\
\text { delas a área de sustentabilidade é responsável } \\
\text { pelo ISP; Os temas de ISP são definidos por } \\
\text { política interna em } 10 \text { empresas; Educação foi } \\
\text { o tema citado por três empresas como priori- } \\
\text { tário para o ISP; Incentivos fiscais é o tipo de } \\
\text { projeto que sete empresas mais utilizam; To- } \\
\text { das as empresas da amostra investem menos } \\
5 \% \text { em ISP relação à sua receita líquida. }\end{array}$ \\
\hline $\begin{array}{l}4.2 \text { A relação das } \\
\text { empresas com as } \\
\text { comunidades }\end{array}$ & $\begin{array}{l}\text { Explorar como é a feita } \\
\text { a gestão do ISP } \\
\text { nas empresas integran- } \\
\text { tes da carteira ISE }\end{array}$ & $\begin{array}{l}4,5,8,10 \\
\text { e } 11\end{array}$ & $\begin{array}{l}\text { O levantamento de necessidades é realizado } \\
\text { por } 10 \text { empresas da amostra; Já o levantamen- } \\
\text { to de satisfação é feito também por } 10 \text { empre- } \\
\text { sas, sendo que a maioria delas, quatro, utiliza } \\
\text { indicadores internos e externos; No total, } 10 \\
\text { empresas avaliam o retorno do ISP e metade } \\
\text { delas, cinco, usa indicadores internos; Com } \\
\text { relação ao impacto das empresas nas comu- } \\
\text { nidades, } 13 \text { empresas da amostra promovem } \\
\text { desenvolvimento sustentável. }\end{array}$ \\
\hline $\begin{array}{l}\text { 4.3 O envolvimento } \\
\text { da alta liderança das } \\
\text { empresas com o ISP }\end{array}$ & $\begin{array}{l}\text { Identificar o envolvi- } \\
\text { mento da alta direção } \\
\text { das empresas com o ISP }\end{array}$ & 2 e 14 & $\begin{array}{l}\text { Em } 11 \text { empresas da amostra, o ISP está asso- } \\
\text { ciado à estratégia da empresa; O envolvimen- } \\
\text { to da alta direção com o tema é alto em nove } \\
\text { empresas. }\end{array}$ \\
\hline $\begin{array}{l}4.4 \text { Os impactos das } \\
\text { ações de ISP em } \\
\text { relação à imagem } \\
\text { reputacional das } \\
\text { empresas }\end{array}$ & $\begin{array}{l}\text { Investigar se os im- } \\
\text { pactos das ações de } \\
\text { ISP contribuem para a } \\
\text { imagem reputacional } \\
\text { das empresas }\end{array}$ & 12 e 13 & $\begin{array}{l}\text { O ISP traz imagem reputacional para } 13 \\
\text { empresas da amostra; A razão que mais tra- } \\
\text { duz a imagem reputacional do ISP para sete } \\
\text { empresas da amostra é o relacionamento com } \\
\text { a comunidade. }\end{array}$ \\
\hline $\begin{array}{l}4.5 \text { Análise das res- } \\
\text { postas das empresas } \\
\text { às perguntas do } \\
\text { questionário ISE } \\
2016 \text { - dimensão } \\
\text { social }\end{array}$ & $\begin{array}{l}\text { Comparar as informa- } \\
\text { ções da pesquisa quali- } \\
\text { tativa com as respostas } \\
\text { fornecidas pelas empre- } \\
\text { sas ao questionário } \\
\text { ISE } 2016 \text { - dimensão } \\
\text { social. }\end{array}$ & $\begin{array}{l}\text { Ques- } \\
\text { tionário } \\
\text { ISE } 2016 \\
\text { - dimen- } \\
\text { são social } \\
\text { SOC } \\
15,15.2 \\
15.3 \text { e } \\
15.4 \text {. }\end{array}$ & $\begin{array}{l}13 \text { empresas responderam que promovem ini- } \\
\text { ciativas de ISP; } 12 \text { empresas levam em conta } \\
\text { a importância de se obter resultados concre- } \\
\text { tos em relação ao investimento nas iniciativas } \\
\text { apoiadas e consideram a avaliação dos resul- } \\
\text { tados obtidos. Somente uma delas respon- } \\
\text { deu que tem auditoria sobre os resultados e } \\
\text { gestão das iniciativas apoiadas; } 12 \text { empresas } \\
\text { afirmaram que definem de forma clara a es- } \\
\text { tratégia, indicadores e metas específicas para } \\
\text { o investimento social e apenas uma sinalizou } \\
\text { que não o faz; Quanto à avaliação regular dos } \\
\text { resultados,13 empresas afirmaram que fazem; } \\
\text { Com relação à utilização de incentivos fiscais } \\
\text { para o ISP, } 13 \text { empresas o fazem. }\end{array}$ \\
\hline
\end{tabular}

Fonte: dados da pesquisa. 


\section{CoNSIDERAÇões finais}

O ISP vem sendo percebido por muitas empresas como estratégico, pois sua gestão, na maioria das empresas da amostra, está subordinada à área de sustentabilidade, confirmando a teoria de Pimentel (2011), segundo a qual a empresa pode se aproximar das questões sociais críticas para o seu negócio, desde que isso seja feito de forma alinhada às diretrizes de sustentabilidade e às estratégias de negócio.

A definição sobre em quais temas de ISP a empresa deve investir é uma tarefa importante, pois é o direcionamento a respeito dos assuntos em que a empresa quer focar. Entendeu-se, por meio da pesquisa, que eles são definidos de maneira formal, seguindo uma política, diretriz ou outra orientação corporativa. Porém, quanto à sua escolha e em qual investir, percebe-se que há diferenças entre as empresas, pois se nota uma preferência por educação em parte delas e se observa que, em uma segunda análise, os temas publicados nos relatórios de sustentabilidade, integrados ou socioambientais, conferem quase que na sua totalidade com os mencionados durante as entrevistas.

Com relação à escolha do tipo de projeto em que vai se investir, existe uma preferência por projetos de incentivo fiscal e, depois, por projetos próprios, confirmando a teoria de Melo Neto e Froes (2004), que destacam que, na relação empresa-comunidade, deve-se seguir alguns critérios como o tipo e a relação, se direta, por meio de projetos sociais próprios, ou indireta, por intermédio de doações e apoios.

Quanto ao volume aportado pelas empresas em ISP, embora o percentual anual não seja alto em relação à receita líquida, como as empresas da carteira ISE têm resultado anualmente positivo de acordo com os relatórios de sustentabilidade, integrados ou socioambientais, os valores financeiros em reais destinados ao tema são, na sua maioria, consideráveis. Como complemento, foi realizada uma análise comparativa do valor investido em ISP citado na pesquisa qualitativa em relação ao publicado nos relatórios, e se percebe que, em sua grande maioria, os valores conferem com os mencionados durante as entrevistas e/ou preenchimento dos questionários.

A forma como é feita a gestão do ISP deixa transparecer o quanto o tema está ou não ligado à estratégia do negócio e o quan- 
to de importância ele tem para a empresa. Assim, para se atingir o primeiro objetivo específico deste estudo, que é o de investigar como é feita a gestão do ISP nas empresas da carteira ISE 2016, pode-se afirmar que ele foi atingido, mediante as informações já relatadas, permitindo compreender como o tema é gerido na dimensão social, ou seja, qual a área responsável pelo ISP, como os temas sociais são definidos, qual o tema prioritário para a empresa, qual tipo de investimento social que a empresa mais utiliza e quanto ela investe anualmente em ISP.

O levantamento das necessidades das comunidades já é realidade para a maioria dos entrevistados, embora a forma como isso é realizado não mostre consenso. Assim, a teoria de Reis e Medeiros (2012) foi confirmada: as empresas são agentes de promoção do desenvolvimento econômico, colaborando na criação de uma consciência global que possibilita engajar a todos na construção de uma sociedade economicamente próspera e socialmente justa.

No levantamento da satisfação das comunidades em relação aos projetos sociais implementados, percebe-se que as empresas que já o fazem acreditam na sua importância. Porém, com relação à forma como é feito, por exemplo, no levantamento das necessidades, não existe unanimidade por parte das empresas.

A avaliação do retorno do ISP é um processo necessário no ambiente corporativo, uma vez que envolve recursos humanos e financeiros da empresa e relacionamento com a comunidade. Dada a importância do exposto e tendo como objetivo geral deste estudo analisar como as empresas integrantes da carteira ISE 2016 avaliam o retorno do ISP, pode-se afirmar que ele foi concretizado e confirmou a teoria de Melo Neto e Froes (2004), segundo a qual a forma como é feita a avaliação do ISP é muito importante e exige a observação de determinados procedimentos para uma apuração eficiente sobre o retorno do ISP. As entrevistas realizadas na pesquisa permitiram apurar que muitas empresas já o fazem. Porém, quanto à metodologia empregada pelas empresas, existe uma preferência por indicadores internos, seguida da utilização de ambos os indicadores internos e apurados por terceira parte.

No processo de avaliação, deve-se levar em conta o impacto das ações da empresa na comunidade e de que forma ele pode contribuir 
para a melhoria e a sustentabilidade delas, como mencionado por Melo Neto e Froes (2004). Assim, após a pesquisa, verifica-se que as empresas têm consciência do seu papel social perante seus entornos e se preocupam em deixar um legado por meio de iniciativas socioambientais, que vão além de promover qualidade de vida e buscam o desenvolvimento sustentável das comunidades.

O envolvimento da alta liderança com o ISP é vital para que ele flua em todos os níveis da empresa e seja compreendido por todos. Dada a relevância deste assunto, a investigação sobre o grau de envolvimento da alta direção da empresa com o ISP, que é o segundo objetivo específico deste estudo, foi satisfatória, na medida em que a maioria das empresas entrevistadas confirmou a teoria de Porter e Kramer (2006), para quem esse envolvimento é considerado estratégico, pois o tema social está inserido na estratégia do negócio e pressupõe a participação da alta liderança.

O terceiro e último objetivo específico, de investigar se os impactos das ações de ISP contribuem para a imagem reputacional da empresa, confirmando assim a teoria de Machado Filho (2006), de que as atividades de responsabilidade social podem ajudar a criar ou manter o capital reputacional da empresa, foi confirmado pela quase totalidade das empresas entrevistadas, nas respostas afirmativas de que o ISP gera imagem reputacional.

A imagem reputacional gerada pelos impactos das ações de ISP é uma forma de verificar os ganhos que ele traz, não só para as comunidades com as quais a empresa se relaciona, como para ela própria. Para muitos entrevistados, traz relacionamento com a comunidade, seguido de imagem de marca, o que, sem dúvida, estreita o relacionamento da empresa com o seu entorno, pois, enquanto agente produtivo, muitas vezes, além de gerar empregos, a organização passa a ter também consumidores locais, em retribuição ao investimento local.

Nenhuma das empresas entrevistadas citou que a imagem reputacional gerada pelo ISP é refletida na melhora dos índices da bolsa, embora duas empresas, tenham afirmado que o ISP contribui muito para o crescimento das exigências anuais do questionário do ISE e outras duas tenham citado que todos os itens são importantes. 
Na avaliação das perguntas respondidas pelas empresas ao questionário dimensão social do ISE 2016, percebe-se que elas levam em conta a importância de se obter resultados concretos em relação ao ISP e consideram a avaliação dos resultados das iniciativas apoiadas.

A estratégia, os indicadores e as metas específicas também são pontuados como positivos, bem como, a avaliação dos resultados adquiridos e a frequência da apuração de resultados. $\mathrm{O}$ investimento social com a utilização de incentivos fiscais também foi citado pelas empresas.

Conclui-se, por fim, que existem processos de avaliação por parte da maioria das empresas da carteira ISE 2016 no que se refere à apuração do retorno do ISP. Embora não exista um consenso sobre qual o melhor método a ser utilizado, notou-se empenho e comprometimento com verificações que sejam capazes de nortear a tomada de decisão, visando à correta aplicação dos recursos da empresa, a fim de contribuir para a melhoria na qualidade de vida a que se propõe as ações sociais empreendidas.

Com relação às contribuições, espera-se com os resultados deste estudo ter apresentado três contribuições, duas para o ambiente corporativo e uma para a comunidade acadêmica. A primeira contribuição é direcionada para as empresas que realizam ISP e já avaliam o seu retorno, no sentido de reforçar a importância desse feito e orientar novas estratégias a partir do benchmarking oferecido por este estudo. Como segunda contribuição, espera-se que as empresas que realizam o ISP, e que ainda não avaliam o seu retorno, possam ser motivadas a fazê-lo de forma formal, a fim de aprimorar os seus controles, ações e resultados.

Como terceira contribuição, espera-se que este estudo tenha gerado ganhos para a comunidade acadêmica, além de inspirar a realização de outros trabalhos que venham a se debruçar sobre o papel das empresas na construção do desenvolvimento sustentável das comunidades do entorno. Especialmente no que se refere aos estudos acerca da Carteira ISE, nota-se largo espaço a ser preenchido por novos estudos voltados aos aspectos sociais de tais empresas. 


\section{REFERÊNCIAS}

AES ELETROPAULO. Relatório de Sustentabilidade 2015. Disponível em: <http://relatorios2015.aesbrasilsustentabilidade.com.br/eletropaulo/>. Acesso em: 9 dez. 2016.

ANDION, Carolina; BECKER, Yara; VICTOR, Ingrid. Is Private Social Investment a form of public goods coproduction? An Overview of the brazilian reality. Disponível em: https:// papers.ssrn.com/sol3/papers.cfm?abstract_id=2129004 / Acesso em: 2 mai. 2016.

BANCO DO BRASIL. Governança da Responsabilidade Socioambiental. Disponível em: <http://www45.bb.com.br/docs/ri/ra2015/pt/05.htm >. Acesso em 13 dez. 2016.

BNDES. Terceiro setor e desenvolvimento social. Relato setorial nº 3, jul. 2001. Disponível em: $<$ www.bndes.gov.br/SiteBNDES/export/sites/default/bndes_pt/Galerias/Arquivos/conhecime nto/relato/tsetor.pdf>. Acesso em: 6 dez. 2016.

BRASKEM. Relatório Anual 2015. Disponível em: <https://www.braskem.com.br/relatorioanual-2015https://www.braskem.com.br/inovacao>. Acesso em: 9 dez. 2016.

CALDAS, C. B.; TAMBOSI FILHO, E.; VIEIRA, A. M. Governança Corporativa e Sustentabilidade: uma relação necessária. Revista UNIABEU, v. 7, p. 353-369, 2014.

COELHO, Queiroz, Michele. Uma proposta de avaliação para o Investimento Social Privado. Revista de Gestão Social e Ambiental. São Paulo, v. 1, n. 2, mai./ago. 2007.

COOPER, Donald R.; SCHINDLER, Pamela S. Métodos de pesquisa em Administração. São Paulo: Bookman, 2011.

COPEL. Relatório de Sustentabilidade 2015. Disponível em:

$<$ http://www.copel.com/hpcopel/root/sitearquivos2.nsf/arquivos/relatorio2015/\$FILE/RelAnu al15.pdf>. Acesso em: 9 dez. 2016.

CPFL Energia. Relatório Anual 2015. Disponível em: <http://www.cpfl.com.br/institucional/ relatorio-anual/Documents/ra-cpfl-2015.pdf>. Acesso em: 9 dez. 2016.

DAHER, Wilton de Medeiros. Responsabilidade Social Corporativa, 1. ed. São Paulo: Saint Paul, 2006.

DEGENSZAJN, André. Avaliação como aprendizagem. In: FUNDAÇÃO ITAÚ SOCIAL et al. (Org.). Avaliação para o investimento social privado: metodologias. São Paulo: Fundação Santillana, 2013, p. 11-16.

DRUCKER, Peter F. O melhor de Peter Drucker: O Homem. São Paulo: Nobel, 2001.

ENGIE ENERGIA. Relatório de Sustentabilidade 2015. Disponível em:

<http://www.mediagroup.com.br/HOST/tractebel/rao/2015/pt/>. Acesso em: 9 dez. 2016.

FERNANDES, Djair Roberto. Uma contribuição sobre a construção de indicadores e sua importância para a gestão empresarial. Rev. FAE. Curitiba, v. 7, n. 1, p. 1-18, jan./jun. 2004.

FREYRE, Gilberto. Sociologia - Introdução ao estudo dos seus princípios. São Paulo: É Realizações, 2009. 
GIFE. Investimento Social Privado. Disponível em: <http://gife.org.br/investimento-socialprivado/>. Acesso em 10 dez. 2016.

GIL, Antonio Carlos. Estudo de Caso. São Paulo: Atlas, 2009.

. Como elaborar projetos de pesquisa. São Paulo: Atlas, 2002.

ISE. O que é o ISE. Disponível em: <www.isebvmf.com.br/index.php?r=site/co>. Acesso em: 10 dez. 2016.

KARKOTLI, Gilson. Responsabilidade Social Empresarial. Petrópolis: Vozes, 2007.

LIGHT. Relatório de Sustentabilidade 2015. Disponível em:

$<$ http://www.light.com.br/Repositorio/Sustentabilidade/Relatorio_Sustentabilidade_2015.pdf >. Acesso em: 10 dez. 2016.

LOJAS RENNER. Gestão Social. Investimento Social Privado. Disponível em:

http://www.lojasrenner.com.br/responsabilidade-social. Acesso em: 10 dez. 2016.

MACHADO FILHO, Cláudio Pinheiro. Responsabilidade social e governança: o debate e as Implicações: responsabilidade social, instituições, governança e reputação. São Paulo: Thomson, 2006.

MELO NETO, Francisco Paulo de; FROES, César. Gestão da Responsabilidade Social Corporativa: o caso brasileiro. Rio de Janeiro: Qualitymark, 2004.

MILANI FILHO, M. A. F. Responsabilidade social e Investimento Social Privado: entre o discurso e a evidenciação, R. Cont. Fin. São Paulo, v. 19, n. 47, p. 89-101, mai./ago. 2008. Disponível em: <http://www.spell.org.br/documentos/ver/6349/responsabilidade-social-einvestimento-social-privado--entre-o-discurso-e-a-evidenciacao>. Acesso em: 09 dez. 2016.

NATURA. Relatório Anual 2015. Disponível em: http://www.natura.com.br/relatorioanual/2015/relatorio-anual-2015. Acesso em: 10 dez. 2016.

OI. Relatório Anual de Sustentabilidade 2015. Disponível em: $<$ http://ri.oi. com.br/conteudo_pt.asp?idioma $=0 \&$ conta $=28 \&$ tipo=43589 >. Acesso em: $10 \mathrm{dez} .2016$.

OLIVEIRA, José Antonio Puppim. Empresas na sociedade: sustentabilidade e responsabilidade social. Rio de Janeiro: Elsevier, 2013.

OTERO, Martina Rillo. Contexto e prática da avaliação de iniciativas sociais no Brasil: Temas atuais. São Paulo: Peirópolis, 2012.

PIMENTEL, Melissa Porto. Da filantropia ao Investimento Social Privado estratégico. Disponível em: <http://captacao.org/recursos/artigos/317-da-filantropia-ao-investimentosocial-privado-estratégico>. Acesso em: 9 dez. 2016.

PORTER Michael E.; KRAMER, Mark R. The link between competitive advantage and corporate social responsibility. Harvard business review, 2006. Disponível em: <http://kantakji. com/media/3307/1135.pdf >. Acesso em: 9 dez. 2016.

PRODANOV, Cleber Cristiano: FREITAS, Ernani Cesar de. Metodologia do trabalho científico: Métodos e técnicas da pesquisa e do trabalho acadêmico. Novo Hamburgo: Feevale, 2013. 
REIS, Carlos Nelson; MEDEIROS, Luiz Edgar. Responsabilidade social das empresas e balanço social - Meios propulsores do desenvolvimento econômico e social. São Paulo: Atlas, 2012. SANTANDER. Sustentabilidade. Disponível em: <https://www.santander.com.br/br/osantander/sustentabilidade>. Acesso em: 10 dez. 2016.

SUL AMERICA SEGURO. Responsabilidade Socioambiental. Disponível em: <http://portal. sulamericaseguros.com.br/data/pages/8A61648E46534E830146543BC30945D E.htm>. Acesso em: 10 dez. 2016.

SZÉKELY, Miguel. Vantagens e complexidades das avaliações de impacto. In: FUNDAÇÃO ITAÚ SOCIAL et al. (Org.). Avaliação para o investimento social privado: metodologias. São Paulo: Fundação Santillana, 2013.

TELEFONICA. Relatório Anual de Sustentabilidade 2015. Disponível em: <

http://www.telefonica.com.br/servlet/Satellite?blobcol=urldata\&blobheader=application $\%$ 2Fp df\&blobkey=id\&blobtable=MungoBlobs\&blobwhere=1385589354347\&ssbinary=true $>$. Acesso em: 10 dez. 2016.

VOLTOLINI, Ricardo. O valor estratégico do Investimento Social Privado. Disponível em: $<$ http://site.gife.org.br/artigo-o-valor-estrategico-do-investimento-social-privado-11944.asp >. Acesso em: 9 dez. 2016.

Recebido em: 21-6-2017

Aprovado em: 30-8-2017

Avaliado pelo sistema double blind review.

Editor: Coordenação do PPGA/UMESP

Disponível em http://mjs.metodista.br/index.php/roc 